\title{
NOVA ESPÉCIE DE BACHIA E A PRESENÇA DE B. DORBIGNYI (DUMÉRIL \& BIBRON) NO SUDOESTE DE MATO GROSSO, BRASIL (SAURIA, GYMNOPHTHALMIDAE)
}

\author{
Maria Ignêz Castrillon ${ }^{1}$ \\ Christine Strussmann ${ }^{2}$
}

\begin{abstract}
A NEW SPECIES OF BACHIA AND THE OCCURRENCE OF B. DORBIGNYI (Duméril \& Bibron) in Southwestern Mato Grosso, Brazil (Sauria, GymnoPHTHALMIDAE). A new species of gymnophthalmid lizard with reduced members (genus Bachia) is described after three specimens obtained at Cáceres $\left(16^{\circ} 10^{\prime} \mathrm{S}\right.$, $57^{\circ} 41^{\prime} \mathrm{W}$ ), in the State of Mato Grosso, western Brazil. Specimens were found under or inside rotting logs in forested or partially disturbed areas and are primary associated to the so called "cerradão" vegetation. Bachia cacerensis sp.n., belongs to the "bresslaui" group and is characterized by the unique dorsal color pattern, with seven longitudinal dark lines on a cream ground color; 49-51 transverse dorsal scale rows; 35 scales around midbody; 38 longitudinal ventral scale rows. Anterior limbs generally with four unharmed apical scales, resembling toes; posterior limbs with a single, unharmed apical scale. A specimen of Bachia dorbignyi (Duméril \& Bibron, 1839) collected at the municipality of Jauru ( $\left.15^{\circ} 14^{\prime} \mathrm{S}, 58^{\circ} 44^{\prime} \mathrm{W}\right)$, near Cáceres, is also described. In the Brazilian territory, B. dorbignyi has been previously recorded only for the State of Rondonia.

KEY WORDS. Gymnophthalmidae, Bachia cacerensis, new species, Bachia dorbignyi, new record, western Brazil
\end{abstract}

O gênero Bachia, de pequenos lagartos de chão com membros locomotores reduzidos, é exclusivamente neotropical, ocorrendo desde a Costa Rica até o Paraguai (sempre a leste dos Andes) e em algumas ilhas do Caribe. Com base nos trabalhos de DiXon (1973), HoogmoEd \& DiXON (1977), MCDiARMID \& DEWEESE (1977) e AVILA-PIRES (1995), são reconhecidas atualmente 16 espécies de Bachia. Para o Mato Grosso, no oeste do Brasil, a literatura registra a presença de apenas dois representantes do gênero: B. scolecoides (Vanzolini, 1961) e B. bresslaui (Amaral, 1935).

Durante levantamentos da herpetofauna realizados em áreas de cerradão (EITEN 1972, para uma caracterização desta unidade fitofisionômica) no município de Cáceres, no sudoeste de Mato Grosso, foram encontrados três indivíduos de uma espécie ainda não descrita de Bachia.

1) Universidade do Estado de Mato Grosso. Caixa Postal 242, 78200-000 Cáceres, Mato Grosso, Brasil.

2) Endereço para correspondência: Rua Antonio Dorileo 508, ap. 34, Residencial Coxiponês, Bairro Coophema, 78085-600 Cuiabá, Mato Grosso, Brasil.

E-mail: eunectes@zaz.com.br 
Posteriormente, trabalhando em área de mata no município de Jauru, Mato Grosso (aproximadamente $160 \mathrm{~km} \mathrm{NW}$ de Cáceres), foi encontrado um indivíduo de $B$. dorbignyi (Duméril \& Bibron, 1839). VANZOLINI (1961) corrigiu a localidade-tipo ("Santa Cruz du Chili") para Santa Cruz de la Sierra, Bolivia. Bachia dorbignyi também está presente no sudeste do Peru (DIXON 1973) e norte do Paraguai (Hellmich 1960, apud DiXON 1973). O único espécime registrado na literatura como procedente do Brasil foi coletado no Rio Manoel Correia (Fig. 1), tributário de $2^{\mathrm{a}}$ ordem do Rio Guaporé, em Rondônia (VANZOLINI 1961).

No presente artigo, apresenta-se a caracterização dos exemplares da nova espécie de Bachia e de $B$. dorbignyi obtidos no sudoeste de Mato Grosso.

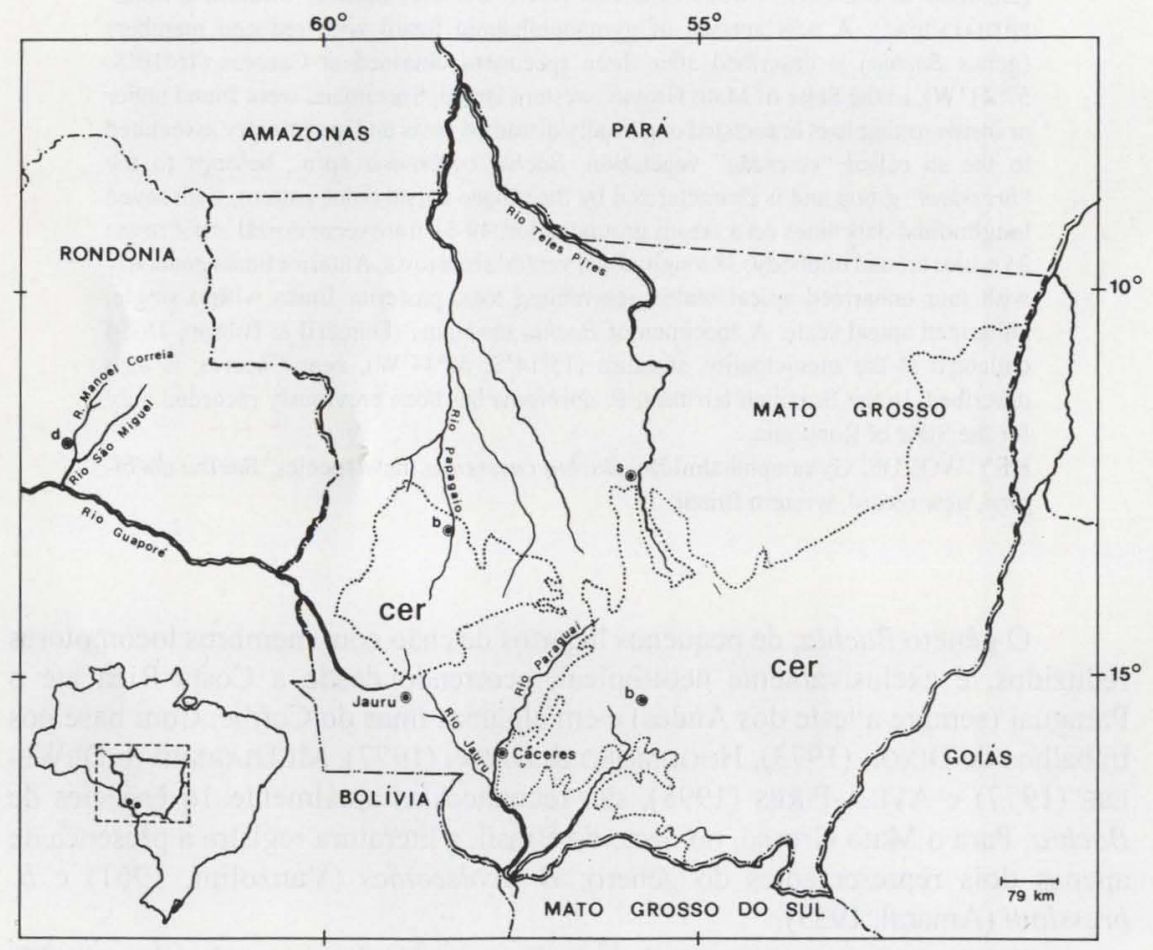

Fig. 1. Posição relativa do estado de Mato Grosso, da localidade-tipo da nova espécie de Bachia (Cáceres) e do município de onde provém o exemplar de $B$. dorbignyi referido neste trabalho (Jauru). Também estão indicados, conforme a literatura, os locais de coleta de outras espécies de Bachia em Mato Grosso (s - B. scolecoides e, b-B. bresslaui) e do único registro anterior de $B$. dorbignyi em território brasileiro, Rondônia (d). As linhas pontilhadas representam o limite aproximado dos cerrados (cer) em Mato Grosso. Além destes limites, situam-se: o Pantanal, no extremo sul e sudoeste; uma ampla faixa de áreas de transição, nas regiões de Jauru e Cáceres (cerrado + florestas estacionais semideciduais) e no médio norte do estado (cerrado + florestas umbrófilas); a floresta umbrófila, a noroeste. 


\section{MATERIAL E MÉTODOS}

As siglas das instituições citadas no texto referem-se às seguintes coleções: ZUEC - coleção de vertebrados do Museu de História Natural da Universidade Estadual de Campinas (UNICAMP, Campinas); UFMT - coleção de vertebrados da Universidade Federal de Mato Grosso (Cuiabá); UNEMAT - coleção de répteis e anfíbios da Universidade do Estado de Mato Grosso (Cáceres).

Nas descrições dos exemplares da série-tipo de Bachia cacerensis sp.n., e do exemplar de $B$. dorbignyi, os números separados por barra (/) indicam as contagens de escamas à direita e à esquerda, num mesmo exemplar. Os critérios utilizados para a notação do número de anéis caudais (e do comprimento da cauda), em exemplares com a cauda mutilada e/ou regenerada, seguem VANZOLINI (1961).

Na descrição da folidose cefálica, a denominação da maior parte das escamas segue o uso corrente (e.g., como em VANZOLINI 1961 e em DiXON 1973). Para descrever as temporais, adotamos a terminologia empregada por HOOGMOED \& DIXON (1977). Para descrever as pré-oculares, a loreal, a mental e as gulares, foram utilizados os critérios de DixON (1973; veja também AVILA-PIRES 1995); para as genianas e pré-gulares, os de DonNelly et al. (1992).

\section{Bachia cacerensis sp.n.}

Figs 2-4a

Holótipo fêmea. BRASIL, Mato Grosso: Cáceres (Cerradão da ZPE - Zona

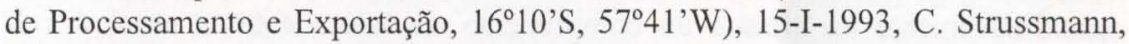
M.I. Castrillon \& M.A. Carvalho leg., ZUEC 01523 (ex-UFMT 1896).

Localidade-tipo. Brasil, Mato Grosso: Cáceres.

Parátipos. BRAsIL, Mato Grosso: Cáceres (em área de cerradão parcialmente alterada, periantrópica, no Curtume Tannery, ZPE de Cáceres), macho, 14-I-1993, C. Strussmann, M.I. Castrillon \& M.A. Carvalho leg., ZUEC 01899 (ex-UFMT 1849); Cáceres (Gleba Facão), fềmea, 24-VI-1994, M.I. Castrillon \& E.L. Silva leg., ZUEC 01900 (ex-UNEMAT 0009).

Etimologia. O nome específico é um adjetivo toponímico, em alusão ao município de Cáceres, no sudoeste de Mato Grosso, de onde procedem todos os exemplares da série-tipo.

Diagnose. Lagarto pequeno, de corpo cilíndrico e alongado, com membros locomotores reduzidos e cauda mais longa que o corpo. Pertence ao "grupo bresslaui" de espécies do gênero Bachia (sensu DixON 1973), possuindo escamas dorsais de aspecto hexagonal, carenadas e imbricadas. As ventrais são retangulares, lisas e justapostas. Membros locomotores anteriores geralmente terminados por quatro escamas apicais, sem garras, assemelhando-se a dígitos. Membros posteriores terminados por uma única escama apical, sem garra. Escamas pré-frontais ausentes, interparietal presente. Um poro pré-anal. Poros femorais $2 / 2 \mathrm{em}$ machos e 2/2 ou inexistentes em fêmeas. Fileiras transversais de escamas dorsais 49-51; escamas em um anel corporal completo no meio do corpo 35; fileiras transversais de ventrais 36-38. Escamas de cor fundamental areia, salpicadas de castanho-escuro 
em maior ou menor grau. Padrão de colorido dorsal: sete listras escuras sobre fundo claro ao longo do corpo e nove listras escuras sobre fundo claro ao longo da cauda. Nos flancos, uma ampla faixa escura que desaparece na cauda (dando lugar às duas listras escuras adicionais aí presentes).

\section{Descrição do holótipo}

Rostral baixa, visível de cima, cerca de duas vezes mais larga do que alta e em contato posterior com a totalidade da margem anterior da frontonasal. Frontonasal trapezóide, mais larga do que longa, em contato lateral com a nasal e em contato posterior com a frontal e com a primeira e mais longa supraocular. Pré-frontais ausentes. Frontal pentagonal, mais longa do que larga, com vértice posterior truncado e em contato com a totalidade da margem anterior da interparietal.

Parietais muito grandes (são as maiores escamas do topo da cabeça, ocupando em conjunto cerca de $50 \%$ de sua superfície), separadas na linha média pela interparietal. Anteriormente, cada parietal está em contato breve (equivalente, em extensão, à sutura entre $o$ vértice da frontal e a interparietal) com a $1^{a}$ supraocular e em contato mais amplo com a frontal (toda a extensão da margem anterior interna da parietal), com a $2^{\mathrm{a}}$ supraocular e com a postocular (cada uma das quais ocupa cerca de $50 \%$ da extensão total da margem anterior externa da parietal). Interparietal estreita e alongada, mais curta do que as parietais; sua maior largura é inferior à de qualquer outra escama do topo da cabeça.

Nasal estreita e alongada, em contato posterior com a $1^{\text {a }}$ supraocular e com a loreal, e em contato inferior com a $1^{\mathrm{a}}$ e $2^{\mathrm{a}}$ supralabiais. Narina localizada aproximadamente na metade do comprimento da sutura entre a nasal e a $1^{\text {a }}$ supralabial. Loreal aproximadamente quadrangular, em contato com a nasal, com a $2^{\mathrm{a}}$ e $3^{\mathrm{a}}$ supralabiais, $1^{\mathrm{a}}$ subocular, pré-ocular, $1^{\mathrm{a}}$ superciliar e ainda com a $1^{\mathrm{a}}$ supraocular. Supraoculares $2 / 2$, sendo a $1^{\mathrm{a}}$ (anterior) muito alongada, separando a frontal da nasal. Esta $1^{a}$ supraocular está em contato anterior com a frontonasal, a nasal e a loreal, e em contato posterior com a parietal, impedindo o contato entre a frontal e a $2^{\mathrm{a}}$ supraocular. Superciliares $2 / 2$, a $1^{\mathrm{a}}$ (anterior) cerca de 1,5 vezes mais longa do que a $2^{\mathrm{a}}$ (posterior). Suboculares $3 / 2$, a $2^{\mathrm{a}}$ muito mais longa e separada da loreal pela $1^{\mathrm{a}}$ subocular, de tamanho equivalente ao da narina (na face esquerda, a $1^{\text {a }}$ subocular é bem mais longa que as demais e está em contato breve com a loreal). Última subocular também pequena (pouco maior que a $1^{\mathrm{a}}$ ), retangular e em contato com a postocular e com a $6^{a}$ ( $5^{a}$ na face esquerda) supralabial. Uma pré-ocular pequena, em forma de vírgula e situada na comissura palpebral, separando a $1^{\text {a }}$ supraciliar da $1^{\mathrm{a}} \mathrm{e} 2^{\mathrm{a}}$ suboculares. Uma postocular, cuneiforme e equivalente à loreal em tamanho, em breve contato com a temporal primária superior (separando a parietal das duas últimas supralabiais).

Supralabiais $7 / 6$, a $2^{\mathrm{a}}$ em contato com a nasal e a loreal; a $3^{\mathrm{a}} \mathrm{em}$ contato com a loreal e com a $1^{\mathrm{a}}$ e $2^{\mathrm{a}}$ suboculares (somente a loreal e a $1^{\mathrm{a}}$ subocular, na face esquerda); $4^{\mathrm{a}}$ e a $5^{\mathrm{a}}$ em contato com a $2^{\mathrm{a}}$ subocular (na face esquerda, a $4^{\mathrm{a}}$ supralabial entra em contato com a $1^{a}$ subocular); a $6^{a}$ com largura anterior reduzida e em contato com a $2^{\mathrm{a}}$ e $3^{\mathrm{a}}$ suboculares (na face esquerda, a $5^{\mathrm{a}}$ supralabial em contato com a $1^{\mathrm{a}} \mathrm{e}$ $2^{\mathrm{a}}$ suboculares) e com a postocular; a última supralabial em contato amplo com as 
duas temporais primárias e em contato pontual com a postocular. Duas temporais primárias (a superior, de 2,5 a três vezes maior que a inferior) e duas temporais secundárias (aproximadamente iguais em tamanho). Abertura auditiva ausente.
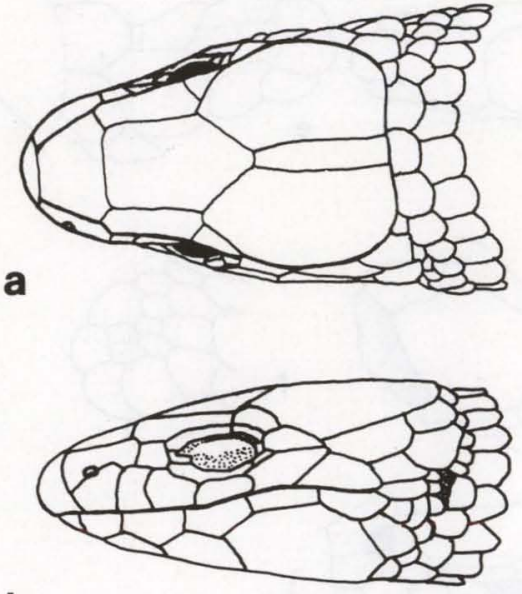

b

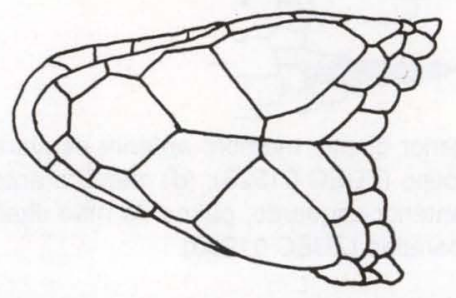

d
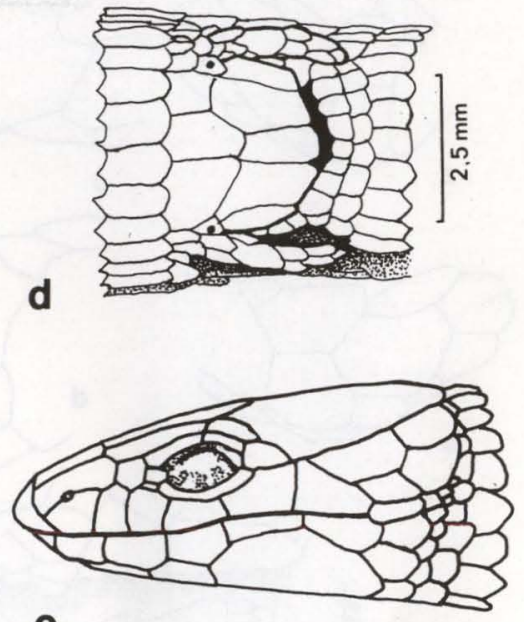

e

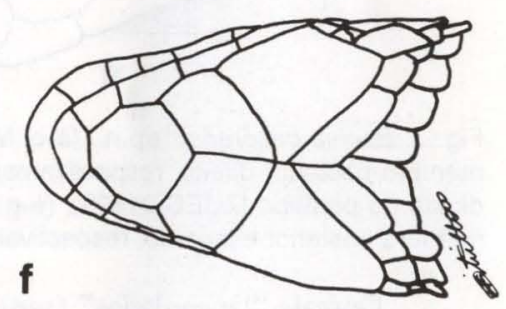

Fig. 2. Bachia cacerensis sp.n.. (a-c) Vista dorsal, vista lateral esquerda e vista ventral da cabeça do holótipo (ZUEC 01523); (d) região pré-anal do holótipo; (e-f) vista lateral esquerda e vista ventral da cabeça do parátipo (ZUEC 01900).

Mental trapezóide, mais larga do que longa. Infralabiais 5/5, estando a terceira aproximadamente na linha do olho. Pós-mental cerca de quatro vezes maior do que a mental, heptagonal e um pouco mais comprida do que larga. Dois pares de genianas, o $1^{\circ}$ par em contato lateral com a $2^{\mathrm{a}}$ e $3^{\mathrm{a}}$ infralabiais e em amplo contato na linha média. As genianas do $2^{\circ}$ par, cerca de 1,5 vezes maiores que as do $1^{\circ}$ par, são separadas na linha média por duas pré-gulares estreitas, alongadas e oblíquas e estão em contato lateral com a $3^{\mathrm{a}}, 4^{\mathrm{a}}$ e $5^{\mathrm{a}}$ infralabiais (Fig. 2c).

Sulco cervical presente; mais evidente nas laterais do pescoço e inaparente na região gular. Sulco lateral iniciando no $11^{\circ}$ anel corporal e de comprimento equivalente a 16/16 anéis corporais.

Nucais (desde o sulco cervical até o anel correspondente à inserção do membro anterior): nove. Fileiras de gulares (entre o sulco cervical e as interbraqui- 
ais): nove. Interbraquiais, seis: um par mediano de escamas grandes, retangulares e, a cada lado, um par distal de escamas menores. A anterior, mais alongada, corresponde a cerca de $2 / 3$ do comprimento da escama interbraquial mediana.
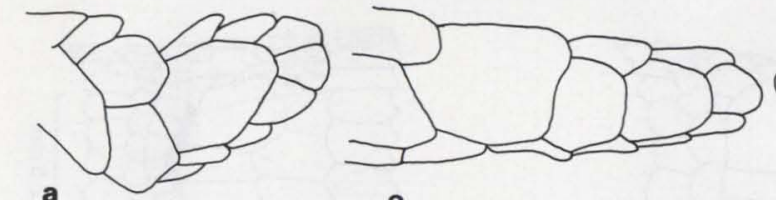

c
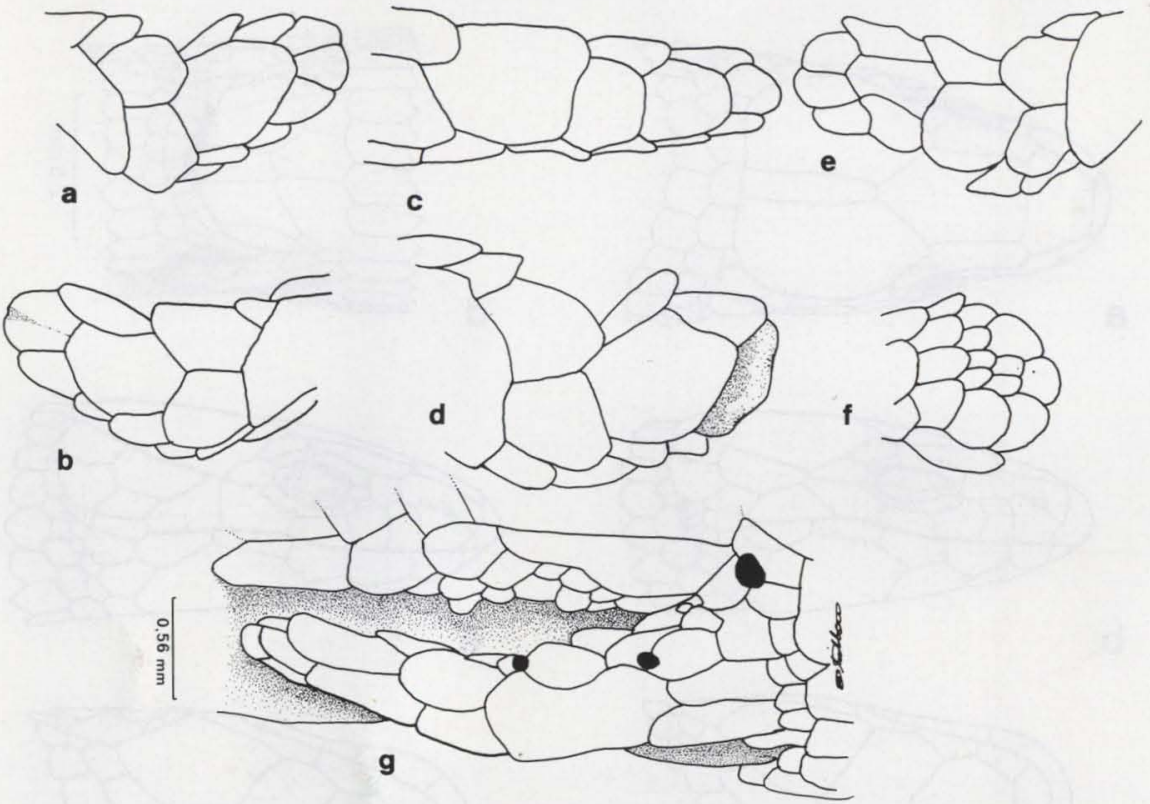

Fig. 3. Bachia cacerensis sp.n.. (a-c) Membro anterior direito, membro anterior esquerdo e membro posterior direito, respectivamente, do holótipo (ZUEC 01523); (d) membro anterior direito do parátipo (ZUEC 01899); (e-g) membro anterior esquerdo, palma da mão direita e membro posterior esquerdo, respectivamente, do parátipo (ZUEC 01900).

Dorsais "lanceoladas" (sensu DIXON 1973), distintamente mais longas do que largas (aproximadamente 4,5 vezes). Embora sejam pentagonais, com bordo anterior reto e vértice voltado para trás, as dorsais estão imbricadas e dispostas em fileiras não longitudinais, de modo a parecerem hexagonais. As dorsais da metade posterior do corpo (e as escamas da face superior da cauda) apresentam, cada uma, dois sulcos laterais longitudinais, os quais separam entre si três quilhas baixas: uma central, um pouco mais larga, e duas externas, mais estreitas e ainda mais baixas. Ventrais lisas, estreitas e alongadas, de bordos posteriores livres e arredondados, justapostas e algo mais largas do que as escamas das três primeiras fileiras de escamas dorsais.

Número de fileiras transversais de escamas dorsais (desde o sulco cervical até o bordo anterior do $1^{\circ}$ anel completo após a abertura cloacal): 51. Fileiras transversais de ventrais (entre as interbraquiais e as pré-anais): 38 . Fileiras longitudinais de ventrais na porção anterior, no meio e na porção posterior do corpo: 10, 9 e 8. Número de escamas em um anel corporal no meio do corpo: 35 (26 dorsais + 9 ventrais). Número de escamas no $13^{\circ}$ anel corporal: 32 ; número de escamas no $46^{\circ}$ anel corporal: 38 . Número de anéis caudais: $34+x$ (cauda mutilada). 

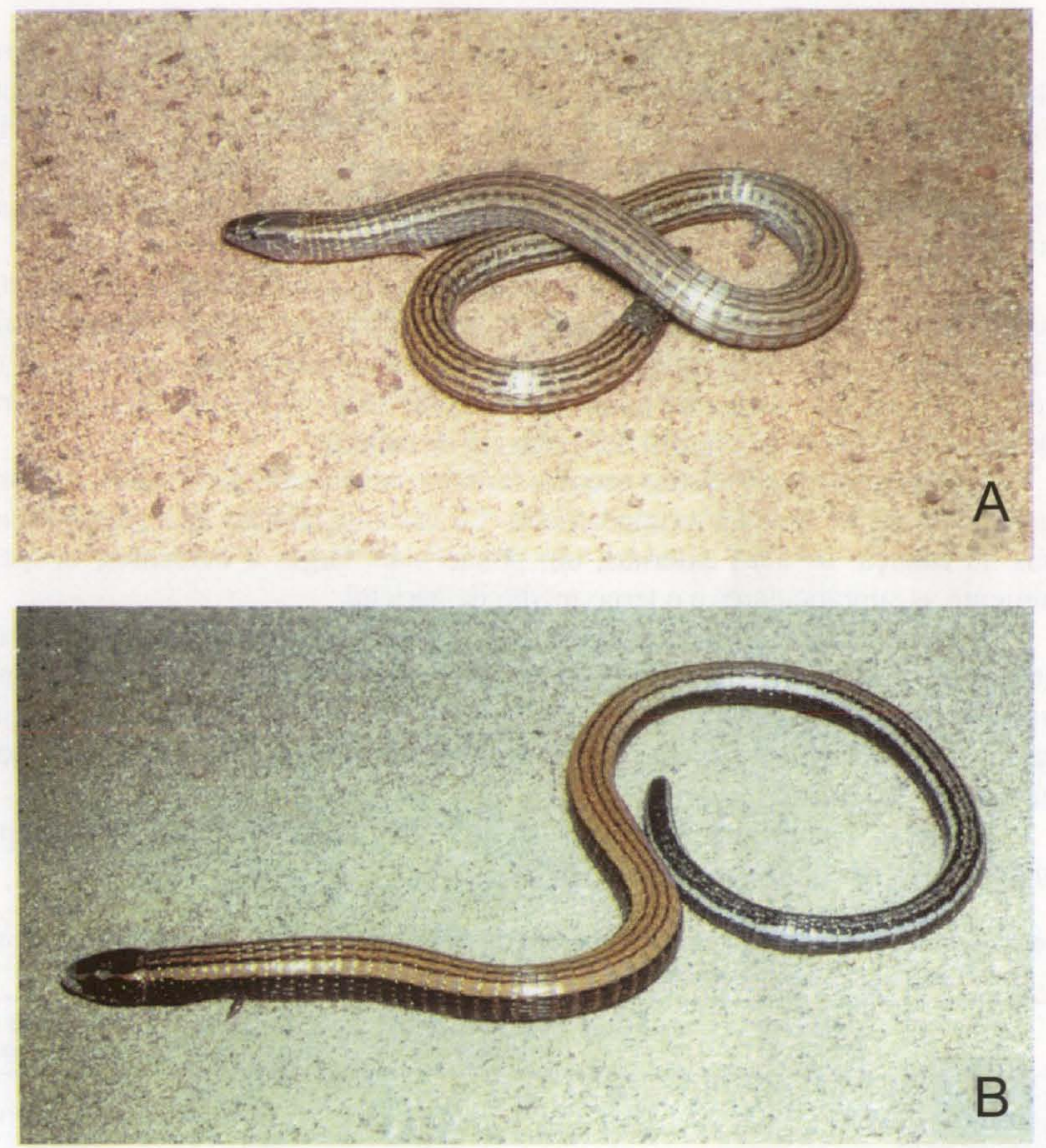

Fig. 4. (a) Aspecto geral, em vida, de um dos parátipos de Bachia cacerensis sp.n. (ZUEC 01899); (b) aspecto geral, em vida, do espécime de Bachia dorbignyi (UFMT 2221).

Região pré-anal composta por uma fileira anterior e uma fileira posterior, cada uma com três escamas centrais aumentadas. A fileira posterior apresenta, ainda, uma escama estreita e alongada em cada borda lateral. À frente desta, situa-se, em uma pequena escama, o poro pré-anal. Poros pré-anais: $1 / 1$; poros femorais ausentes (Fig. 2d).

Membro anterior direito de comprimento equivalente a cerca de 2,5 anéis corporais, com quatro escamas apicais, inermes e subiguais, semelhantes a dígitos (Fig. 3a). Membro anterior esquerdo de comprimento equivalente a cerca de 3 anéis corporais, com três escamas apicais (Fig. 3b). A escama central, distintamente maior que as laterais, apresenta vestígios de divisão, especialmente em sua porção basal. Membros posteriores de comprimento equivalente a cerca de 3,5 anéis corporais, com uma escama apical, inerme (Fig. 3c). 
Padrão de colorido. Dorso de tom fundamental areia, com sete listras castanho-escuras: uma mediana, duas paravertebrais, duas dorsolaterais e duas laterais, que constituem o limite superior de uma ampla faixa escura lateral (Fig. 4a). No limite inferior desta há outra listra escura, não tão evidente, que se inicia ao nível da inserção do membro anterior. Esta listra, situada no limite entre as dorsais e as ventrais, é mais nítida na parte posterior do corpo e ainda mais na cauda.

As listras escuras têm largura equivalente à de uma escama dorsal. A listra escura dorsolateral tem bordas irregulares, menos definidas que as das demais listras escuras longitudinais, e assim se apresenta em toda sua extensão, até o final da cauda. É, também, a única a ter início após o colar nucal: as demais listras escuras estão presentes (ainda que pouco definidas) já na cabeça.

Os espaços entre as listras escuras formam seis faixas claras, cada uma com largura equivalente à de aproximadamente 1,5 escamas dorsais. Há quatro faixas claras na cabeça: as duas externas, um pouco mais largas e evidentes, ocupam totalmente as supraoculares e o terço médio da parietal.

A faixa lateral escura tem largura equivalente à de 5-6 escamas. Escamas do ventre de cor fundamental areia, salpicadas de castanho-escuro. Na cauda, há nove listras escuras (a faixa lateral escura desaparece). Na porção ventral da cauda, as escamas são ainda mais salpicadas de castanho, dando à região tonalidade geral mais escura que a do ventre.

Medidas. Comprimento rostro-anal 66,0 mm; outras medidas do holótipo, bem como dos parátipos, constam da tabela I.

Tabela I. Medidas dos exemplares da série-tipo de Bachia cacerensis, expressas em milimetros, com exceção do peso, expresso em gramas.

\begin{tabular}{lccc}
\hline \multicolumn{1}{c}{ Caracteres } & $\begin{array}{c}\text { ZUEC } 01523 \\
\text { Holótipo fêmea }\end{array}$ & $\begin{array}{c}\text { ZUEC 01899 } \\
\text { Parátipo macho }\end{array}$ & $\begin{array}{c}\text { ZUEC 01900 } \\
\text { Parátipo fêmea }\end{array}$ \\
\hline Comprimento rostro-anal & 66,0 & 82,3 & 66,4 \\
Comprimento da cauda & $34,9+(\mathrm{x})$ & $62,4+(14,0)$ & $79,8+(11,3)$ \\
Distância axila-virilha & 51,3 & 62,6 & 49,0 \\
Comprimento da cabeça & 6,7 & 7,9 & 6,9 \\
Largura da cabeça & 4,3 & 5,6 & 4,6 \\
Largura no meio do corpo & 4,9 & 5,8 & 4,9 \\
Comprimento do membro anterior & 2,5 & $2,7^{*}$ & 2,5 \\
Comprimento do membro posterior & 2,6 & 4,0 & 3,3 \\
Peso & - & - & 1,8 \\
Razăo entre a soma do comprimento dos membros & 0,099 & 0,107 & 0,118 \\
locomotores (anterior + posterior) e a distância axila-virilha & & & \\
\hline
\end{tabular}

${ }^{\star}$ Escamas apicais parcialmente mutiladas.

Variação. Em ambos os parátipos, o número de suboculares difere do encontrado no holótipo: 3/3 no exemplar ZUEC 01900 (Fig. 2e), 3/4 no ZUEC 01899. A postocular não toca a temporal primária superior (permitindo o contato entre a parietal e a última supralabial) e o $2^{\circ}$ par de genianas está em breve contato na linha média (Fig. 2f).

O sulco lateral inicia-se no $12^{\circ}$ anel corporal e tem comprimento equivalente a 15/15 anéis corporais no parátipo ZUEC 01900 e 17/18 anéis corporais no parátipo ZUEC 01899. Este último apresenta somente quatro interbraquiais: um par mediano de escamas grandes, retangulares e, a cada lado, apenas uma escama, estreita e alongada. 
Nos parátipos, os números de fileiras transversais de escamas dorsais e de escamas ventrais diferem daqueles registrados para o holótipo: 49/37 no ZUEC 01899 e 50/36 no ZUEC 01900 (51/38, respectivamente, no holótipo). No parátipo ZUEC 01899 o número de fileiras longitudinais de ventrais na porção posterior do corpo é o mesmo existente na porção anterior: dez, não havendo redução como no holótipo e no parátipo ZUEC 01900 . O parátipo ZUEC 01900 apresenta 31 escamas no $13^{\circ}$ anel corporal e 36 escamas no $46^{\circ}$ anel corporal ( 32 e 38 , respectivamente, no holótipo).

Ambos os parátipos possuem cauda parcialmente regenerada; há $39+(16)$ anéis caudais no parátipo ZUEC 01899 e 63+(12) anéis caudais no parátipo ZUEC 01900. Há $2 / 2$ poros femorais em cada um dos parátipos (Fig. 3g), em contraste com a ausência destes no holótipo.

Em ambos os parátipos, apenas uma escama da fileira pré-anal anterior toca a escama mediana da fileira posterior, enquanto no holótipo duas escamas da fileira anterior tocam a escama mediana da fileira posterior.

No parátipo ZUEC 01899, as extremidades dos membros anteriores estão mutiladas mas, no lado direito, permitem evidenciar a presença de mais de uma escama apical (Fig. 3d). No parátipo ZUEC 01900, cada um dos membros anteriores apresenta quatro escamas apicais bem distintas (Fig. 3e,f). Não há variação perceptível nos exemplares da série-tipo quanto à conformação dos membros posteriores e também no padrão de colorido.

\section{Comparações}

Bachia cacerensis pertence ao grupo bresslaui (fide DiXON 1973), até então composto por três espécies: $B$. bresslaui, $B$. scolecoides e $B$. panoplia. As características comuns aos representantes do grupo incluem a presença de escama interparietal, de supraoculares e superciliares; 2-2 poros femorais e 1-1 poros pré-anais nos machos; escamas dorsais e laterais (em B. panoplia, também as ventrais) de aparência hexagonal, lanceoladas, carenadas e imbricadas; ventrais quadrangulares e justapostas (não em panoplia).

Bachia cacerensis difere de todas as demais espécies do "grupo bresslaui" no padrão de colorido dorsal. De B. panoplia distingue-se facilmente, também, por possuir escamas ventrais lisas ao invés de carenadas, pela ausência de pré-frontais (bem desenvolvidas e em amplo contato medial, em panoplia) e pela condição menos desenvolvida e inerme dos membros posteriores (estes possuem quatro artelhos providos de garras, tanto em panoplia como em scolecoides).

A nova espécie também difere de B. scolecoides pela ausência de pré-frontais (pequenas e completamente separadas na linha mediana, em scolecoides). A ausência de pré-frontais em $B$. cacerensis poderia ser explicada da mesma forma que para B. bresslaui onde, segundo VANZOLINI (1961), esta condição provavelmente se deve à "... fusão de uma pré-frontal como a de scolecoides com a verdadeira primeira supraocular".

A forma mais próxima de $B$. cacerensis é B. bresslaui. As principais diferenças entre as duas espécies, além do padrão de colorido, estão na conformação dos membros anteriores: geralmente com quatro escamas apicais em cacerensis e 
invariavelmente terminados por uma única escama apical em bresslaui (AMARAL 1935: Fig. 2; VANZOLINI 1961: 201; MACLEAN 1973: 81; DiXON 1973: Fig. 4; observação pessoal). Os membros posteriores, embora semelhantes em conformação, possuem comprimentos relativos distintos: em B. cacerensis, representam em média $6,06 \%$ da distância axila-virilha $(n=3 ; \mathrm{s}=0,88)$. Em cinco exemplares de $B$. bresslaui oriundos de Chapada dos Guimarães, Mato Grosso, e depositados na Universidade de Brasilia, o comprimento dos membros posteriores representa $\mathrm{c}$. $4,86 \%$ da distância axila-virilha $(s=0,96)$.

Também a conformação da placa anal difere entre representantes de $B$. bresslaui de Chapada dos Guimarães e dois dos exemplares da série-tipo de $B$. cacerensis. Em bresslaui, há sempre duas escamas (centrais e subiguais) na fileira pré-anal anterior tocando a escama mediana da fileira posterior. Embora esta seja a condição presente no holótipo de cacerensis, em ambos os parátipos há apenas uma escama (grande, losangular, bem diferenciada das escamas vizinhas) da fileira pré-anal anterior tocando a escama mediana da fileira posterior.

\section{História natural}

O holótipo de Bachia cacerensis foi encontrado em meio ao material apodrecido de um tronco caído no chão, no interior de mancha de cerradão localizada ao sul da sede do município de Cáceres, entre o leito do Rio Paraguai e a Serra do Facão. Esta mancha florestada, além de pequena (cerca de 45 ha de área total) e isolada, correspondia a área destinada à implantação da primeira etapa da ZPE de Cáceres, tendo sido posteriormente destruída.

Um parátipo foi encontrado durante remoção de leiras por trator, em área industrial originalmente ocupada por cerradão e contígua à mancha florestada citada acima. O outro parátipo estava sob tronco em decomposição, em área de cerradão parcialmente alterada, no local conhecido como Gleba Facão (imediações do morro Facão, a sudeste da sede do município de Cáceres). Também esta área encontra-se atualmente degradada, em decorrência de assentamentos agrícolas desordenados.

Tanto o macho como a fêmea coletados na ZPE em janeiro apresentavam gônadas em condição reprodutiva, estando a fêmea com dois folículos vitelogênicos. O exame do conteúdo dos tubos digestivos dos três exemplares evidenciou a presença de um quilópode Scolopendromorpha (no ZUEC 1900) e restos de formas adultas de Insecta.

\section{Distribuição}

Bachia cacerensis é conhecida apenas do município de Cáceres, cuja sede situa-se na margem esquerda do Rio Paraguai (Fig. 1), a uma altitude de aproximadamente $120 \mathrm{~m}$ acima do nível do mar. Embora os sítios originais de coleta estejam completamente degradados, é possível que a espécie venha a ser encontrada em outras áreas de cerradão e em matas semidecíduas em localidades vizinhas, particularmente ao longo da Serra das Araras. O estabelecimento de áreas preservadas com boa representatividade de ambientes de cerradão, no entorno de Cáceres, é imperioso para a conservação desta nova espécie.

\section{Comentários adicionais}

Entre os representantes do "grupo bresslaui", B. panoplia tem distribuição amazônica (restrita a Manaus e Depto. Vaupés, Colômbia). Bachia scolecoides 
também está restrita a uma localidade, situada em área de transição entre os cerrados e a floresta amazônica, no médio-norte de Mato Grosso (Fig. 1). Já B. bresslaui parece possuir área de distribuição bem mais ampla, que inclui tanto áreas de transição como ambientes francamente abertos.

Bachia bresslaui foi descrita por AMARAL (1935) com base em um único exemplar, oriundo do "interior do Estado de São Paulo". Ao analisar um segundo espécime, obtido em Utiariti, Mato Grosso (cerca de $340 \mathrm{~km}$ ao norte de Cáceres), VANZOLINI (1966) questionou a procedência do tipo. Posteriormente, MACLEAN (1973) e MCDIARMID \& FOSTER (1987) apresentaram informações sobre dois exemplares adicionais de B. bresslaui, um procedente de Brasília, DF, outro do "Parque Nacional Cerro Corá, Departamiento Amambay", no Paraguai.

Estes registros, somados à presença da espécie em Chapada dos Guimarães (ARAÚJo 1994; G. Colli, comunicação pessoal), permitiriam conferir maior credibilidade à questionada ocorrência em São Paulo. Além disso, permitiriam traçar para $B$. bresslaui uma ampla área de ocorrência, na qual estaria incluída também a da nova espécie. O exemplar descrito e figurado em MCDIARMID \& FOSTER (1987), entretanto, difere dos demais exemplares conhecidos de B. bresslaui quanto ao padrão de colorido dorsal. A natureza desta variação poderá ser melhor avaliada quando exemplares adicionais da região chaquenha estiverem disponiveis para exame.

Bachia cacerensis ocorre em área de transição entre florestas estacionais semideciduais e os cerrados (Fig. 1). As características de seus membros locomotores são também transicionais entre a condição supostamente mais primitiva (a presença de membros mais desenvolvidos, com maior número de dígitos e artelhos, como em B. panoplia e $B$. scolecoides) e aquela mais avançada (membros estiliformes, terminando em escama apical única, como em B. bresslaui). A distribuição das formas conhecidas do grupo bresslaui parece apontar para um cenário evolutivo em que se verificou uma redução no número de dígitos e artelhos à medida em que os representantes do gênero passaram a ocupar áreas mais abertas, do norte para o sul (DIXON 1973; PRESCH 1975). Em solos com pouca cobertura vegetal, escassa serapilheira e pouco material apodrecido, a necessidade de ocupar abrigos subterrâneos teria forçado à fossorialidade, com redução dos membros locomotores e fusão de placas cefálicas.

Outras três espécies de lagartos Gymnophthalmidae (representando os gêneros Colobosaura Boulenger, 1887, Micrablepharus Boettger, 1885 e Pantodactylus Duméril \& Bibron, 1839) foram encontradas em simpatria com B. cacerensis no cerradão da $Z \mathrm{PE}$, em quantidades relativamente altas. Em relatório referente aos levantamentos herpetológicos na área de influência da BR 364, no estado de Rondônia, VANZOLINI (1986: 16) registra que a coleta de indivíduos de Bachia ocorre apenas "em condições especiais" e que "... os microteiídeos do chão e do estrato baixo da mata (...) não são espécies comuns". O mesmo parece não ocorrer em ambientes florestais no domínio dos cerrados (e.g. cerradões, matas ciliares, matas semidecíduas) e mesmo em áreas mais abertas, onde os gimnoftalmídeos (designação atual para os microteídeos) podem estar entre as espécies de maior abundância relativa (VITT 1991; ARAÚJO 1994). 


\section{Bachia dorbignyi (Duméril \& Bibron, 1839) \\ UFMT 2221, Fig. 4b}

Um indivíduo desta espécie foi encontrado sob tronco caído, em área de floresta estacional semidecidual localizada à margem direita do Rio Jauru (integrante da Bacia do alto Rio Paraguai), a montante do Salto da Fumaça (aprox. $15^{\circ} 14^{\prime} \mathrm{S}$, $58^{\circ} 44^{\prime}$ W, Fig. 1). Embora parcialmente ameaçada de destruição (em decorrência de intentados aproveitamentos hidrelétricos no curso do Rio Jauru), a área é relativamente extensa e sua representatividade em regiões limítrofes parece ser bem maior do que aquela dos cerradões em Cáceres.

Por tratar-se de espécie pouco conhecida em território brasileiro, e como subsídio às discussões (AVILA-PIRES 1995) sobre a afinidade entre $B$. dorbignyi e B. peruana (Werner, 1901), passamos a descrever as características do exemplar obtido em Jauru.

\section{Descrição}

Nasais, frontonasal, frontal e parietais presentes; interparietal, pré-frontais e supraoculares ausentes. Rostral baixa (escassamente visível de cima), em contato com a frontonasal, separando entre si as nasais. Parietais grandes (equivalentes em tamanho ou pouco menores do que a frontal), em contato na linha média apenas em sua metade posterior. Parietais também em amplo contato com a frontal, com a $2^{\mathrm{a}}$ superciliar, com a temporal primária e com a temporal secundária superior, e em contato pontual com a 5 supralabial. A frontal é a maior escama do topo da cabeça. Tem formato pentagonal e seu vértice, voltado para trás, projeta-se por entre as metades anteriores das parietais, impedindo seu contato na linha média. Superciliares $2 / 2$, a $2^{\mathrm{a}}$ (posterior) mais longa do que a $1^{\mathrm{a}}$ (anterior); suboculares $3 / 3$. Supralabiais $6 / 6$, a quinta em contato estreito com a parietal. Uma temporal primária e três temporais secundárias: a superior maior e a inferior bem menor que as demais.

Mental pequena, mais larga do que longa. Infralabiais $5 / 5$, a terceira aproximadamente na linha do olho. Pós-mental cerca de quatro a cinco vezes maior que a mental, heptagonal e de largura aproximadamente igual ao comprimento. Dois pares de genianas, $01^{\circ} \mathrm{em}$ total contato mediano; o $2^{\circ}$, de forma irregular, em contato mediano apenas na porção anterior. Na porção posterior estão separadas por duas pré-gulares cuneiformes, com vértices voltados para a frente. Lateralmente, cada geniana do $2^{\circ}$ par está em contato amplo com a $3^{\mathrm{a}}$ e a $4^{\mathrm{a}}$ infralabiais e em contato pontual com a $5^{\mathrm{a}}$ infralabial.

Sulco cervical presente, bem marcado em toda a circunferência do pescoço. Sulco lateral iniciando-se no $12^{\circ}$ anel corporal e de comprimento equivalente a 13/13 anéis corporais.

Nucais: 8. Fileiras de gulares: 7. Interbraquiais: 6, sendo um par mediano, de escamas grandes, retangulares e mais longas do que largas. A cada lado destas, um par distal de escamas menores composto por uma escama anterior estreita, correspondendo a cerca da metade do comprimento da escama medial, e uma escama posterior cuneiforme, com vértice voltado para frente e de comprimento aproximadamente igual à metade do comprimento da escama interbraquial mediana. 
Dorsais distintamente mais longas do que largas (aproximadamente 2,5 vezes mais: hexagonais sensu DiXON 1973). Possuem forma pentagonal, com bordo anterior reto e vértice voltado para trás; imbricadas e dispostas em fileiras não longitudinais, parecem hexagonais. Embora aparentemente lisa, cada escama dorsal apresenta uma mancha central oblonga ou arredondada, correspondente a uma pequena depressão (as escamas da cauda apresentam-se, também, desta maneira). Ventrais retangulares, justapostas; as distais um pouco mais estreitas do que as proximais; aparentemente lisas, embora cada escama apresente, como nas dorsais, uma mancha central clara, ovóide, correspondente a uma pequena depressão. Ventrais nitidamente diferenciadas das laterais, de aparência hexagonal e mais estreitas.

Número de fileiras transversais de escamas dorsais: 53. Número de fileiras transversais de ventrais: 39 . Fileiras longitudinais de ventrais na porção anterior, no meio e na porção posterior do corpo: 8,8 e 6 , respectivamente. Número de escamas em um anel corporal no meio do corpo: 26 (18 dorsais +8 ventrais). Número de escamas no $13^{\circ}$ e no $46^{\circ}$ anéis corporais, respectivamente: 22 e 28 . Número de anéis caudais: 101 .

Região pré-anal composta por quatro escamas pré-anais: uma anterior e três posteriores, das quais a medial bem menor. Poros pré-anais e poros femorais ausentes.

Membro anterior de comprimento equivalente a cerca de três anéis corporais, com três dígitos providos de garras. Membro posterior de comprimento equivalente ao de um anel corporal, estiliforme, com uma escama apical dividida.

Padrão de colorido. Dorso com três listras escuras (uma mediana e duas paravertebrais), separando entre si quatro faixas longitudinais claras (duas medianas e duas dorsolaterais), em tom amarelo-palha. As listras escuras têm largura equivalente a pouco menos de uma escama dorsal, mas suas bordas são pouco definidas. A listra escura mediana torna-se ainda menos definida na cauda e acaba por coalescer com as outras duas, na extremidade livre desta. As faixas claras dorsolaterais são algo mais largas ( 1,5 a 2 escamas de largura) do que as paravertebrais (aprox. uma escama de largura) e são evidentes ao longo de praticamente todo o corpo. $\mathrm{Na}$ cabeça, são bem distintas desde a margem ântero-lateral da frontal; passam por sobre o olho (acima das supraoculares) e ocupam a borda lateral das parietais. As faixas paravertebrais claras desaparecem próximo à extremidade livre da cauda. Flancos e lateral inferior da cauda castanho-escuros, formando uma faixa de largura equivalente a cerca de cinco escamas, na porção média do corpo. Região ventral também intensamente salpicada de castanho, em tom um pouco mais claro do que na faixa lateral. Em vida (Fig. 4b), a coloração das faixas claras, na metade posterior da cauda, é azulada.

Medidas (em mm). Comprimento rostro-anal: 66,7; comprimento da cauda: 85,5; distância axila-virilha: 49,3; largura do corpo: 4,6; comprimento da cabeça: 5,7; largura da cabeça: 4,3; comprimento do membro anterior: 2,7 ; comprimento do membro posterior: 0,8 ; razão entre a soma do comprimento dos membros (anterior + posterior) e a distância axila-virilha: 0,07. 


\begin{abstract}
AGRADECIMENTOS. Somos gratas ao Marcos A. Carvalho, Everaldo L. Silva e Silvio Rodrigues por auxílio no campo e à família do Sr. José Salu (Faz. Boa Sorte) por apoio logístico durante as atividades em Jauru. $\mathrm{O}$ trabalho não poderia ter sido terminado sem a ajuda de Márcia M. de Abreu e dos biólogos Edna Hardoin e Benedito Rogério, através dos quais obtivemos facilidades laboratoriais junto ao "Projeto Gran Pantanal" (Cooperação Brasil-Alemanha, UFMT). A AZPEC financiou os trabalhos de inventariamento faunístico na área a ser ocupada pela ZPE de Cáceres. Apoio financeiro e/ou institucional às autoras foi providenciado pelo CNPq (processo 301515/91-3) e pela UFMT, durante a vigência de uma bolsa de Desenvolvimento Científico Regional à C. Strussmann, e pela UNEMAT, para M.I. Castrillon. Agradecemos também ao Dr. Ivan Sazima e ao Prof. Paulo Manzani (UNICAMP, Campinas), ao Prof. Francisco Machado (UFMT, Cuiabá) e ao Dr. Guarino Colli (UNB, Brasília) por permitirem o exame de material científico sob sua responsabilidade, e ainda à Dra. Tereza C. Avila-Pires e ao Dr. Miguel T. Rodrigues, pela leitura crítica do manuscrito.
\end{abstract}

\title{
REFERÊNCIAS BIBLIOGRÁFICAS
}

Amaral, A. 1935. Novo genero e especie de lagarto do Brasil. Mem. Inst. Butantan 9: 249-251.

ARAúJo, A.F.B. 1994. Comunidades de lagartos brasileiros, p.58-68. In: L.B. NASCIMENTO, A.T. BERnARdES \& G.A. CotTA (Eds). Herpetologia no Brasil 1. Belo Horizonte, PUC/MG, Fund. Biodiversitas, Fund. Ezequiel Dias, 134p. AvILA-PIRES, T.C.S. 1995. Lizards of Brazilian Amazonia (Reptilia: Squamata). Zool. Verh., Leiden, 299: 1-706.

DiXon, J.R. 1973. A Systematic Review of the Teiid Lizards, Genus Bachia, with remarks on Heterodactylus and Anotosaura. Misc. Publ. Mus. Nat. Hist. Univ. Kansas 57: 1-47.

DonNelly, M.A.; R.W. MCDiaRmiD \& C.W. MYers. 1992. A new lizard of the genus Arthrosaura (Teiidae) from Southern Venezuela. Proc. Biol. Soc. Wash. 105 (4): 821-833.

EITEN, G. 1972. The cerrado vegetation of Brazil. Bot. Rev. 38: 201-341.

Hoogmoed, M.S. \& J.R. DiXoN. 1977. A new species of Bachia (Teiidae, Sauria) from Estado Bolivar, Venezuela, with notes on the zoogeography of the genus. Zool. Med. 51 (2): 25-31.

MACLEAN, W.P. 1973. On the third specimen of Bachia bresslaui (Sauria, Teiidae). Papéis Avulsos Zool., São Paulo, 27 (6): 81-82.

MCDiarmid, R.W. \& J.E. DeWeESE. 1977. The systematic status of the lizard Bachia blairi (Dunn) 1940 (Reptilia: Teiidae) and its occurrence in Costa Rica.

Brenesia 12/13: 143-153.

McDiarmid, R.W. \& M.S. Foster. 1987. Additions to the Reptile Fauna of Paraguay with Notes on a Small Herpetological Collection from Amambay. Stud. Neotrop. Fauna Environ. 22 (1): 1-9.

PrEsCH, W. 1975. The evolution of limb reduction in the teiid lizards, genus Bachia.

Bull. South. Calif. Acad. Sci. 74 (3): 113-121.

VAnZolini, P.E. 1961. Bachia: espécies brasileiras e conceito genérico (Sauria, 
Teiidae). Papéis Avulsos Zool., São Paulo, 14 (22): 193-209. 1966. Sobre o segundo exemplar de Bachia bresslaui (Sauria, Teiidae). Papéis Avulsos Zool., São Paulo, 19 (15): 189-192.

1986. Levantamento herpetológico da área do estado de Rondônia sob a influência da rodovia BR 364. Brasília, CNPq, Relatório de Pesquisa 1, 50p. VITT, L.J. 1991. An Introduction to the Ecology of Cerrado Lizards. Jour. Herpetol. 25 (1): 79-90.

Recebido em 17.IV.1997; aceito em 17.VI.1998. 